\title{
Dendrochronology and climate change study in Nepal: a preview
}

\author{
P. K. Chhetri ${ }^{1}$, K. B. Shrestha ${ }^{2}$
}

$\mathbf{T}^{\mathrm{t}}$ he needs for advanced studies on impacts of climate change have been realized. In this study, the major focus is on changing climatic pattern and increasing natural hazards and its environmental consequences in Nepal. The climatic records of Nepal extend back to a relatively short period and may not adequately represent the range of natural climatic variability. A long term climatic data is needed to understand ongoing climate change phenomenon. In the recent decades dendrochronological data have been widely used in the world as a long term, high resolution, proxy of climate change.

Dendrochronology is a branch of science which deals with the study of tree rings. Dendroclimatology reveals the relationship between past climate events and annual tree growth. The annual rings of trees can be important sources of long-term paleoclimatic data if they are dated accurately. However, the properties of tree rings can vary in response to climate change. Using trees growing in a particular sites where climate has been highly limiting to the process of tree growth, the features of dated rings can be averaged year by year to obtain a time series of the growth response to past variations in climate (Frits, 1976).

Cook et al (2003) and Sano et al (2005) have demonstrated the possibility of reconstructing past climate in Nepal Himalaya by using dendroclimatic techniques. Therefore, dendrochronological study can not only come up with paleoclimatic information, but also help in understanding climate change phenomenon.

\section{Current status of dendrochronological study in Nepal}

Dendrochronological work in Nepal was started by Rudolf Zuber under the supervision of Fritz Schweingruber. This work was followed by many other research scholars (Suzuki, 1990; Bhattacharya et al., 1992; Cook et al., 2003; Sano et al., 2005). Abies spectabilis has been the most studied species but there have been many other potential species, such as Pinus roxburghii, Pinus wallichiana, Tsuga dumosa, Picea smithiana, Juniperus recurva, Ulmus wallichiana, Cedrus deodara, Larix potanini.

\section{Tree ring in climate change study in Nepal}

In Nepal, dendrochronological study began in late 70 s but it was used in climate change study only after 2003. Suzuki (1990) and Bhattacharya et al (1992) hinted about the potentiality of different species for dendroclimatological studies. Cook et al (2003) reconstructed February-June and October-February temperature, back to $1546 \mathrm{AD}$ and 1605, respectively. This was considered as the first reconstructed temperature of Nepal. Each reconstruction confirmed the occurrence of unusually cold temperatures in 1815-1822, which coincided with the eruption of Tambora in Indonesia. The OctoberFebruary climate reconstruction demonstrated evidence of late 20th century global warming trend whereas the February-June temperatures indicated cooling trend since 1960.

Sano et al (2005) reconstructed the past 249 years climate of western Nepal using ring width and wood density of $A$. spectabilis. This reconstructed temperature for the past 249 years showed a warming trend from 1750s until approximately 1790, followed by cooling until 1810, then by a gradual warming trend well up to 1950. A notable cold period continued up to the present which did not support the consensus of recent global warming.

Since various studies considered dendrochronology as an appropriate and effective tool for prediction of past climatic information, only the systematic dendrochronological study can deal with the climate change phenomenon. The potential areas for future

\footnotetext{
${ }^{1}$ Graduate School of Environmental Science, Hokkaido University, Sapparo, Japan. chhetri@www.geo.ees.hokudai.ac.jp

${ }^{2}$ Departments of Biology, University of Bergen, Bergen, Norway. Krishna.shrestha@bio.uib.no
} 
dendrochronological studies in Nepal are discussed below.

\section{Future focus}

Western Nepal climate is influenced by both Eastern and Western Monsoon. So, there is a higher probability of finding potential climatic signals in western Nepal than in eastern Nepal. The southern margin of vegetation distribution (Tropical to temperate margin) has $P$. roxburghii and $P$. wallichiana as highly potential tree species.

More studies should be focused on tree line area to investigate the effect of recent global warming on tree line phenomena. The fluctuation of tree line position, growth dynamics pattern due to the climatic variability and the effect of human land-use can be of interest. For such studies tree line forming species like A. spectabilis, T. dumosa can be used as potential species. The responses of tree line species to the global warming over the last century have been detected in many parts of the Northern Hemisphere (e.g. Rochefort et al. 1994; Peterson et al., 2002) by evaluating tree seedlings, invading above the current tree line.

Only two studies (Schmidt, 1993, Schmidt et al., 1999) were found on archeological sites. Many centuries old Gumbas and Temples. are widely distributed in Nepal. Dendrochronological studies focusing on wood samples from these monuments will help to reveal past environment. The protential for of isotopic tree ring study is also high in Nepal. Many isotopic tree ring studies have already been carried out in India.

Strong dendrochronological network is needed to be developed to understand the current phenomenon of climate change. It should cover a variety of species and ecological conditions. Topography, relief, microcatchments should be considered while collecting samples. Thus, constructed past climate will help us understand the climatic variability in Nepal as well as the whole South Asian region.

\section{Conclusion}

Nepal has a wide distribution of dendroclimatologically potential species; but in comparison to neighbouring countries and other mountainous regions, the related studies have been very limited in Nepal although climate change is more pronounced in Nepal Himalayas and can have severe impacts on livelihoods. Systematic climatic studies based on tree rings can help us understand the ongoing climate change pattern.

So it is recommended that more micro-climate related dendrochronological researches are carried out. Dendrochronology ought to be included in the university curriculum in Nepal.

\section{References}

Bhattacharyya, A., LaMarche Jr. V.C., and Hughes, M.K. 1992. Tree-ring chronologies from Nepal. Tree-Ring Bulletin. 52: 59-66.

Cook E.R., Krusic, P.J. and Jones. P.D. 2003. Dendroclimatic signals in long tree-ring chronologies from the Himalayas of Nepal. International Journal of Climatology 23: 707-732.

Fritts, H.C. 1976. Tree Ring and Climate. Academic Press, London.

Peterson, D.W., Peterson, D.L., Ettl, G.J. 2002. Growth responses of subalpine fir to climatic variability in the Pacific Northwest. Canadian Journal of Forest Research 32: 1503-1517.

Rochefort, R.M., Little, R.L., Woodward, A. and Peterson, D.L. 1994. Changes in sub-alpine tree distribution in western North America: a review of climatic and other causal factors. Holocene 4:89100.

Sano, M., Furuta. F., Kobayashi, O. and Sweda. T. 2005. Temperature variations since the mid-18th century for western Nepal, as reconstructed from tree-ring width and density of Abies spectabilis. Dendrochronologia 23: 83-92.

Schmidt, B. 1993. Dendrochronological research in south Mustang. Ancient Nepal 130-131: 20-25.

Schmidt, B., Wazny, T., Malla. K., Hofs, E. and Khalessi, M. 1999. Chronologies for Historical Dating in High Asia/Nepal. In Tree Ring Analysis: Biological, Methodological and Environmental Aspects (ed) Wimmer, R. and Vetter, R.E. Cabi International, UK, 205-211.

Suzuki, E. 1990. Dendrochronology in coniferous forest around Lake Rara, western Nepal. Tokyo 103: $297-312$. 